\title{
OBITUARY
}

\section{Dr. William G. Cullen}

Dr. Whlliam George Cullen died on June 6, 1973, at Cornwall, Ontario, after a prolonged illness.

Born at Ayr, Ontario, Dr. Cullen graduated in Medicine from the University of Toronto in 1932. After internship at the Toronto Western Hospital, he spent some years in general practice before deciding to specialize in Anaesthesia.

From 1944 to 1946, he was a resident in Anaesthesia under the direct tutelage of Dr. H.R. Griffith and the late Dr. Wesley Bourne. He gained his specialist certificate from the Royal College of Physicians and Surgeons in 1946 and, at that time was appointed to the Attending Staff at the Queen Elizabeth Hospital of Montreal. In 1947, he was appointed to the Teaching Staff in the newly developing Department of Anaesthesia at McGill University, becoming Assistant Professor in 1954. He was a Certified Specialist of the College of Physicians and Surgeons of Quebec, a Diplomate of the American Board of Anesthesiology, Fellow of the American College of Anesthesiologists and of the International College of Anaesthetists and, in 1958, became a Fellow of the Faculty of Anaesthetists, Royal College of Surgeons, England, by election. His interest in the well-being and progress of the specialty was shown by his service as Secretary-Treasurer of the Quebec Division of the Canadian Anaesthetists' Society from 1949 to 1957.

Dr. Cullen became Anaesthetist-in-Chief at the Queen Elizabeth Hospital of Montreal in 1959 and competently guided the Department through the growing pains of hospital expansion. In 1968, in preparation for retirement, he moved to Ontario and a less onerous private practice of Anaesthesia in Cornwall. Unfortunately, he was overtaken by ill-health and was unable to enjoy for long his new home with its beautiful site on the St. Lawrence River.

He will be remembered by his colleagues as a kind and gentle doctor who always had his patients' best interests at heart and who was meticulous in their care. His patience and understanding as a teacher will not be forgotten by his students interns, residents, and nurses - who are now scattered throughout Canada.

Dr. Cullen is survived by his wife, Amy, and by their two daughters, Nancy and Judy, and son, Tom.

Deirdre M.M. GiLlies, M.D. 